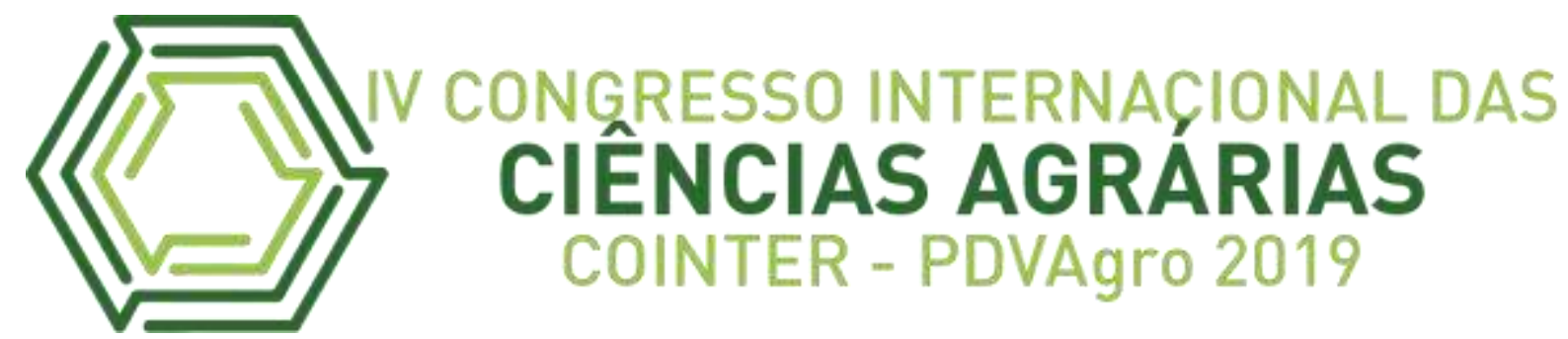

\title{
CARACTERIZAÇÃO DA PRODUÇÃO DE HORTALIÇAS NO MUNICÍPIO DE URUÇUÍ-PI
}

\section{CARACTERIZACIÓN DE LA PRODUCCIÓN DE VERDURAS EN LA CIUDAD DE URUÇUÍ-PI}

\section{CHARACTERIZATION OF VEGETABLES PRODUCTION IN THE CITY OF URUÇUÍ-PI}

\author{
Apresentação: Comunicação Oral \\ Miguel Antonio Rodrigues ${ }^{1}$; Fabiano de Oliveira Silva ${ }^{2}$; Tyago Henrique Alves Saraiva \\ Cipriano $^{3}$; Paulo Gustavo do Nascimento Barros ${ }^{4}$; Anne Karoline de Jesus Ribeiro ${ }^{5}$
}

DOI: https://doi.org/10.31692/2526-7701.IVCOINTERPDVAgro.2019.0028

\begin{abstract}
Resumo
A agricultura familiar tem grande representatividade no meio rural, produzindo de forma sustentável, no entanto, as políticas públicas de apoio a esse segmento deixam a desejar principalmente quando a atividade econômica limita-se ao sustento da família, não aparecendo nas estatísticas de movimentação financeira do município. Este estudo teve como objetivo analisar as unidades produtoras de hortaliças do município de Uruçuí-Pi, com finalidade de comercialização. Para tanto, realizou-se uma pesquisa junto aos representantes das famílias da agricultura familiar que comercializam hortaliças no mercado municipal, localizado em UruçuíPI, onde se obteve informações de natureza primária sobre sua trajetória e limitações estruturais. As principais hortaliças cultivadas pelo grupo de produtores estudados são: melancia, abóbora, batata-doce, coentro, pimenta, melão, pimenta e alface, os quais apresentam facilidade na produção e na comercialização. Observou-se que há predominância de representantes da agricultura familiar atuando ma produção e comercialização de hortaliças, direcionando para a necessidade de organização em forma de associação ou cooperativa. Há predominância de pessoas do município de Uruçuí-PI, o que mostra indicativo de desenvolvimento endógeno. Os
\end{abstract}

\footnotetext{
${ }^{1}$ Professor Mestre do curso de Engenharia Agronômica, Instituto Federal do Piauí - campus Uruçuí, e-mail: miguel.rodrigues@ifpi.edu.br

${ }^{2}$ Acadêmico do curso de Bacharelado em Engenharia Agronômica, Instituto Federal do Piauí - Campus Uruçuí, e-mail: fabianodeoliveirasilva3@gmail.com

${ }^{3}$ Acadêmico do curso de Licenciatura em Ciências Biológicas, Instituto Federal do Piauí - Campus Uruçuí, e-mail: tyagohenrique98@gmail.com

${ }^{4}$ Acadêmico do curso de Bacharelado em Engenharia Agronômica, Instituto Federal do Piauí - Campus Uruçuí, e-mail: gustavonb08@gmail.com

${ }^{5}$ Acadêmica do curso de Bacharelado em Engenharia Agronômica, Instituto Federal do Piauí - Campus Uruçuí, e-mail: anneribeiro1234amor@gmail.com
} 
resultados mostraram que há necessidade de intervenção de políticas públicas para apoiar o grupo de produtores, preferencialmente em um espaço unificado, com a finalidade de dar maior visibilidade à produção local, e contribuir para a expansão tanto da quantidade produzida quanto da população que frequenta o mercado municipal para fazer a compra dos produtos, pois há ainda uma desvalorização do que a população nativa produz no município e isso se estende aos órgãos representativos do poder público vinculados à política de apoio aos pequenos produtores.

Palavras-Chave: Agricultura familiar, sustentável, políticas públicas, desvalorização.

\section{Resumen}

La agricultura familiar tiene una gran representación en las zonas rurales, produciendo de manera sostenible; sin embargo, las políticas públicas para apoyar este segmento no son particularmente deseables cuando la actividad económica se limita al apoyo de la familia, no aparece en las estadísticas de movimiento financiero de la familia. municipio. Este estudio tuvo como objetivo analizar las unidades de producción de hortalizas del municipio de Uruçuí-Pi, con fines de comercialización. Con este fin, se realizó una encuesta con los representantes de las familias de agricultores familiares que venden verduras en el mercado municipal, ubicado en Uruçuí-PI, donde se obtuvo información sobre su trayectoria y limitaciones estructurales. Los principales vegetales cultivados por el grupo de productores estudiados son: sandía, calabaza, camote, cilantro, pimiento, melón, pimiento y lechuga, que son fáciles de producir y vender. Se observó que existe un predominio de representantes de la agricultura familiar que trabajan en la producción y comercialización de hortalizas, señalando la necesidad de organización en forma de asociación o cooperativa. Hay un predominio de personas del municipio de Uruçuí-PI, lo que indica un desarrollo endógeno. Los resultados mostraron que existe la necesidad de intervención de políticas públicas para apoyar al grupo de productores, preferiblemente en un espacio unificado, con el fin de dar mayor visibilidad a la producción local y contribuir a la expansión tanto de la cantidad producida como de la población que frecuenta la región. mercado municipal para realizar la compra de los productos, porque todavía existe una devaluación de lo que produce la población nativa en el municipio y esto se extiende a los organismos representativos del gobierno vinculados a la política de apoyo a los pequeños productore.

Palabras Clave: Agricultura familiar, sostenible, política pública, devaluación..

\footnotetext{
Abstract

Family agriculture has a large representation in rural areas, producing in a sustainable way; however, the public policies to support this segment are not particularly desired when the economic activity is limited to the support of the family, not appearing in the statistics of financial movement of the family. County. This study aimed to analyze the vegetable production units of the municipality of Uruçuí-Pi, for marketing purposes. To this end, a survey was conducted with the representatives of family farming families who sell vegetables in the municipal market, located in Uruçuí-PI, where information on their trajectory and structural limitations was obtained. The main vegetables grown by the group of producers studied are: watermelon, pumpkin, sweet potato, coriander, pepper, melon, pepper and lettuce, which are easy to produce and sell. It was observed that there is a predominance of representatives of
} 
family farming working in the production and marketing of vegetables, pointing to the need for organization in the form of association or cooperative. There is a predominance of people from the municipality of Uruçuí-PI, which shows indicative of endogenous development. The results showed that there is need for intervention of public policies to support the group of producers, preferably in a unified space, in order to give greater visibility to local production, and contribute to the expansion of both the amount produced and the population that frequents the region. municipal market to make the purchase of the products, because there is still a devaluation of what the native population produces in the municipality and this extends to the representative bodies of the government linked to the policy of support to small producers.

Keywords: Family farming, sustainable, public policy, devaluation.

\section{Introdução}

A agricultura familiar encontra diversas barreiras para a expansão de suas atividades e colocação de sues produtos no mercado, uma vez que a produção em larga escala, marcada pela presença de tecnologias que otimizam a produtividade acabam vencendo os espaços da produção local, mesmo sendo praticada em outros estados e agregando o custo do transporte, como é o caso da maior parte da hortaliças comercializadas no município de Uruçuí-PI.

A agricultura familiar pode ser conceituada como a forma de organização da produção em que a família é ao mesmo tempo proprietária dos meios de produção e executora das atividades produtivas, e tem como seu principal foco o desenvolvimento rural sustentável, que procura explorar de forma diversificada um conjunto de atividades rurais economicamente viável, socialmente equitativa e ambientalmente sustentável (NEVES, 2006).

A agricultura familiar pode ser apontada como um segmento estratégico para o desenvolvimento do país, haja vista que $84,40 \%$ dos 5,17 milhões de estabelecimentos rurais do Brasil são dessa natureza (IBGE, 2006), a qual produz 70\% dos alimentos consumidos pelos brasileiros todos os dias, e ainda responde por $38 \%$ da renda agropecuária e ocupa quase $75 \%$ da mão de obra do campo (MDA, 2012).

Tabela 01 - Brasil: Estabelecimentos e áreas correspondentes

\begin{tabular}{ccc}
\hline Categoria & Total de Estabelecimentos rurais (\%) & $\begin{array}{c}\text { Área total cultivada } \\
(\%)\end{array}$ \\
\hline Agricultura Familiar & 84,4 & 24,3 \\
\hline Agricultura Patronal & 15,6 & 75,7 \\
\hline
\end{tabular}

Fonte: IBGE, Censo Agropecuário, 2006. 
$\mathrm{Na}$ tabela 01, observa-se que a agricultura patronal detém a maior parte das terras, embora o número de estabelecimentos seja bem inferior. Por outro lado, a agricultura familiar representa $85,2 \%$ de todos os estabelecimentos agrícolas do Brasil.

O segmento Agrícola e Agroindustrial de Uruçuí é uma atividade produtiva, economicamente responsável pelo arranque econômico do Município e mantém uma grande arquitetura socioeconômica na atualidade, além de ser uma atividade de subsistência (o caso da agricultura). Nos últimos anos, tem se tornado cada vez mais tecnificada, por isso é fundamental que a atividade agroindustrial conte com pessoas com maior nível de instrução para acompanhar essa evolução.

De acordo com o as informações do Sindicato dos trabalhadores rurais do município de Uruçuí-PI, existem 18 (dezoito) agricultores que produzem e comercializam produtos de hortas orgânicas e comercializam no mercado de Uruçuí. A problemática da pesquisa volta -se para o seguinte questionamento: como ocorre a produção e comercialização de hortaliças de agricultores familiares do município de Uruçuí-PI? Hipoteticamente, pode-se aprontar: Historicamente, onde há prática do agronegócio como no município de Uruçuí, os agricultores familiares ficam sem oportunidades de participação no processo frente à produção em larga escala; as políticas públicas direcionadas à agricultura familiar apresentam fragilidade no apoio a esse grupo de agricultores; a agricultura familiar do município de Uruçuí é composta por pessoas nativas do próprio município.

Nesse sentido, o objeto desse estudo foi analisar as unidades produtoras de hortaliças do município de Uruçuí-PI, com finalidade de comercialização.

\section{Fundamentação Teórica}

Na concepção de Neves (2006), a Agricultura Familiar pode ser conceituada como a forma de organização da produção em que a família é ao mesmo tempo proprietária dos meios de produção e executora das atividades produtivas, e tem como seu principal foco o desenvolvimento rural sustentável, que procura explorar de forma diversificada um conjunto de atividades rurais economicamente viável, socialmente equitativa e ambientalmente sustentável.

Como se observa na tabela que segue, comparando os modelos da Agricultura Familiar com o Agroexportador (agronegócio), as vantagens deste sobre aquele são visíveis, do ponto de vista das possibilidades de inserção e permanência no mercado. 
Tabela 02: Agricultura Familiar x Modelo Agroexportador

\begin{tabular}{|c|c|}
\hline AGRICULTURA FAMILIAR & $\begin{array}{r}\text { AGROEXPORTADOR } \\
\end{array}$ \\
\hline Pequena Propriedade & Média e Grande Propriedade \\
\hline $\begin{array}{l}\text { Sistema de produção socialmente articulado, } \\
\text { com possibilidade de integração ao mercado }\end{array}$ & $\begin{array}{l}\text { Sistema de produção predominantemente capitalista } \\
\text { integrado ao mercado }\end{array}$ \\
\hline Gestão Familiar & Gestão Profissionalizada \\
\hline Produção diversificada em pequena escala & Produção especializada em alta escala \\
\hline $\begin{array}{l}\text { Intensiva em trabalho e práticas produtivas } \\
\text { convencionais }\end{array}$ & Tecnologias modernas \\
\hline Regularização Fundiária & Concentração Fundiária \\
\hline $\begin{array}{l}\text { Pequena propriedade e redução da } \\
\text { migração do campo para cidade }\end{array}$ & $\begin{array}{l}\text { Domínio do grande capital agroindustrial, } \\
\text { impulsionando o êxodo rural }\end{array}$ \\
\hline $\begin{array}{l}\text { Subsistência - com dificuldade para } \\
\text { reprodução, inserção e integração ao } \\
\text { mercado. }\end{array}$ & $\begin{array}{l}\text { Capitalista - integrado ao mercado } \\
\text { e com capacidade de reprodução }\end{array}$ \\
\hline Pouca competitividade & Competitividade Internacional \\
\hline
\end{tabular}

Fonte: Elaborada a partir de Gualda (2008).

Os representantes do Agronegócio detém a maior parte das terras e do financiamento. Isso mostra a priorização do poder público aos detentores de maior poder aquisitivo e que, em tese, são capazes de posicionar o País no mercado internacional.

A agricultura de grande escala, cognominada de agronegócio, em virtude de seu peso nas exportações e de sua representatividade política, recebe tratamento diferenciado do poder público. A agricultura familiar, embora também tenha acesso ao financiamento a baixas taxas de juros por meio do PRONAF (Programa Nacional de Fortalecimento da Agricultura Familiar), continua enfrentando muitas dificuldades para se manter, pois, apenas o acesso ao crédito oficial não é suficiente para viabilizá-la (HESPANHOL, 2008).

A expansão da agricultura brasileira teve como base a manutenção de uma estrutura de uma distribuição fundiária altamente concentrada, onde uma pequena quantidade de grandes propriedades controla a maioria da terra. $\mathrm{O}$ crédito rural não foi distribuído de forma equitativa entre o conjunto das famílias produtoras, pois foi destinado basicamente aos médios e grandes proprietários, ficando os representantes da agricultura familiar, especialmente os mais pobres e marginalizados excluídos (SORJ, 1980 apud SOUSA, 2008). 
As políticas públicas agrárias brasileiras seguem a lógica do modelo de constituição de estado do país, cuja resultante induziu à concentração de políticas públicas dirigidas à agricultura, que tem privilegiado médios e grandes produtores (SOUSA, 2008).

A mudança nas bases produtivas, a partir da implementação de novas tecnologias, baseada na mecanização intensiva, na agroquímica e associada a uma política agrícola em larga escala, de monocultura e de exportação, ampliou a concentração da propriedade da terra e intensificou o assalariamento e o êxodo rural (PIETRAFESA, 2000 apud SOUSA, 2008 p. 41). A política de crédito adotada no Brasil tinha como objetivos centrais aumentar a oferta de alimentos e modernizar a agricultura, diferentemente de outros países que utilizam o subsídio ao crédito para reduzir a pobreza (BITTENCOURT, 2003). Desde essa perspectiva a redução da pobreza, bem como o privilégio da agricultura familiar não são prioridades da política agrícola do país.

Entretanto, de acordo com o Censo Agropecuário do IBGE (2006), as famílias agricultoras estão dispersas em 4.367.902 de estabelecimentos rurais e, segundo Araújo (2013), respondem por aproximadamente $70 \%$ da produção de feijão, $87 \%$ de mandioca, $59 \%$ de suínos, $58 \%$ e bovinocultura de leite, $46 \%$ de milho, $50 \%$ de aves e ovos, $34 \%$ de arroz, entre outros.

Já a presença do agronegócio predomina nas lavouras de soja, trigo, café e na bovinocultura de corte (ARAÚJO, 2013). Dos 5.175.239 estabelecimentos agropecuários, apenas 807.337 são desse grupo (IBGE, 2006).

\section{Metodologia}

Uruçuí é um município do estado do Piauí, localizado a uma latitude $07^{\circ} 13^{\prime} 46^{\prime \prime}$ sul e a uma longitude $44^{\circ} 33^{\prime} 22^{\prime \prime}$ oeste, estando a uma altitude de 167 metros. Segundo dados do IBGE (2010), sua população até esse ano era de 20.085 habitantes. Conta com extenso território e ocupa o quarto lugar na área geral do estado, estando localizado às margens do rio Parnaíba que divide os estados do Piauí e Maranhão, ficando há $453 \mathrm{~km}$ de Teresina. Está na lista dos municípios brasileiros que mais crescem nos setores econômicos, destacando-se principalmente pelo crescimento do agronegócio. 


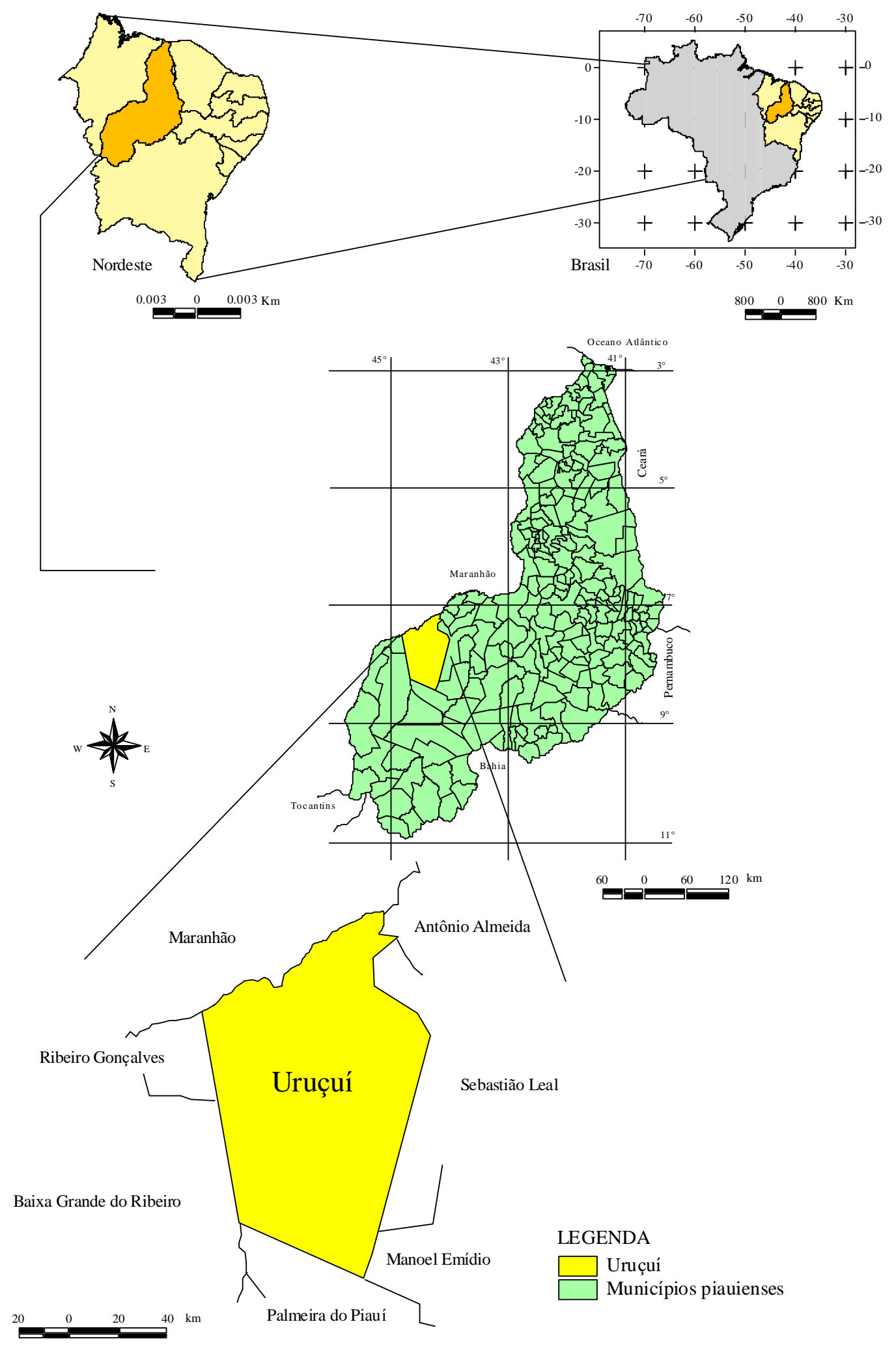

Figura 1: Localização do Município de Uruçuí. Fonte: IBGE (2010). 
A pesquisa foi desenvolvida através da aplicação de questionários semiestruturados aos representantes das famílias da agricultura familiar que comercializam hortaliças no mercado municipal, localizado no município de Uruçuí-PI, onde se obteve informações de natureza primária sobre sua trajetória e limitações estruturais. De acordo com Diehl e Tatim (2004, p.65) dados primários "são aqueles colhidos e registrados pelo próprio pesquisador em primeira mão".

Segundo Bussab e Morettin (2010), o método de Amostragem Aleatória Simples (AAS) é a maneira mais acessível para selecionar uma amostra probabilística de uma população. Assim, a escolha das famílias foi realizada com base na AAS a partir da numeração de 18 cartões, onde cada número representou uma família que produz hortaliças para comercialização, previamente identificada por através do representante desses produtores. Esses cartões foram dobrados, inseridos em uma caixa e retirados ao acaso repetitivamente até que se completasse o total de 5, além da realização de entrevista com um representante dos produtores.

Na sequência foram realizadas entrevistas semiestruturadas "in situ" aos 05 respectivos responsáveis pelas unidades produtoras cujas respostas foram reproduzidas por escrito, e após permissão, também gravadas para transcrição complementar. Cada titular participante assinou um termo de compromisso autorizando a utilização dos dados para pesquisa, desde que se mantivesse a confidencialidade da identidade.

Após a obtenção dos dados elaborou-se matrizes no Microsoft Excel ${ }^{\circledR}$, visando melhor demonstrar as informações coletadas.

\section{Resultados e Discussão}

De acordo com as informações coletadas nos arquivos da organização dos produtores de hortaliças com a finalidade de comercialização do município de Uruçuí, existem atualmente 18 (dezoito) produtores, os quais enfrentam problemas de falta de acompanhamento técnico, transporte para deslocamento dos produtos, bem como motivação e incentivo do poder público, no sentido de viabilizar um espaço comum de produção de hortaliças, onde o associativismo estivesse presente no processo. Isso traria benefícios como redução de custos de produção e posicionamento no mercado.

No contexto, uma alternativa que poderia viabilizar a produção e comercialização dos trabalhadores em análise seria a formação de uma associação, que segundo Balem (2016), as associações e cooperativas podem ser compostas por grupos grandes ou grupos menores, o qual varia de acordo com os interesses dos associados e dos objetivos da organização. A autora 
destaca que quando se tem o objetivo de construir estruturas de armazenagem para frutas por exemplo (câmaras frias), adquirir estruturas de transporte (caminhões apropriados), contratar pessoal especializado para construção de mercados, acessar mercados de longa distância nacionais e internacionais, é necessário um investimento maior. A princípio, a motivação seria a organização do grupo em um espaço comum, para produzir.

Na tabela 2, observa-se que há predominância de produtores do Estado do Piauí, com a presença apenas de um produtor cuja origem é Remanço/BA, e outro no município de Benedito Leite/MA, que faz divisa com o Piauí. Diferentemente do que ocorre com a ocupação das terras com finalidade da produção em larga escala, que não há nenhum produtor piauiense (RODRIGUES et al., 2013).

Os investimentos no cerrado piauiense do setor do agronegócio partem de produtores do Sul e Sudeste do país, que vem em busca de melhores condições de produção, bem como de empresários locais com atividades de apoio à moderna agricultura, com a comercialização de insumos e implementos agrícolas e instalando unidades de produção agroindustriais (REYDON; MONTEIRO, 2006).

Nesse sentido, é possível afirmar que as condições de implantação do cultivo de hortaliças para a comercialização no município de Uruçuí estão caracterizadas por indicativos de crescimento endógeno, que permite um melhor entendimento da dinâmica dos efeitos da política econômica em geral sobre diferentes patamares de crescimento, na medida em que políticas de comércio exterior, fiscal, educacional, de distribuição de renda, de formação de infraestrutura e de incentivos ao progresso tecnológico constituem-se em externalidades ao processo produtivo (ARRAES; TELES, 2000).

Tabela 3: Caracterização das unidades produtoras de hortaliças - Uruçuí-PI

\begin{tabular}{|c|c|c|c|c|c|c|}
\hline ORIGEM & $\begin{array}{c}\text { ÁREA } \\
\text { TOTAL }\end{array}$ & $\begin{array}{l}\text { HORTALIÇAS } \\
\text { CULTIVADAS }\end{array}$ & $\begin{array}{c}\text { POSSE DA } \\
\text { TERRA }\end{array}$ & $\begin{array}{c}\text { AQUISIÇÃO } \\
\text { DA TERRA }\end{array}$ & $\begin{array}{l}\text { APOIO DO } \\
\text { GOVERNO }\end{array}$ & $\begin{array}{l}\text { PREÇO DO } \\
\text { HECTARE }\end{array}$ \\
\hline $\begin{array}{l}\text { Remanço- } \\
\text { BA }\end{array}$ & $200 \mathrm{~m}^{2}$ & $\begin{array}{l}\text { Melancia, } \\
\text { Abóbora, } \\
\text { Batata, } \\
\text { Coentro, } \\
\text { Pimenta, } \\
\text { Melão, } \\
\text { Pimentão, } \\
\text { Alface. }\end{array}$ & Própria & Doação & Não & $\begin{array}{l}\text { Não sei, pois } \\
\text { foi doada }\end{array}$ \\
\hline Uruçuí- PI & 1 tarefa & $\begin{array}{l}\text { Melancia, } \\
\text { Abóbora, } \\
\text { Batata, } \\
\text { Coentro, } \\
\text { Pimenta, }\end{array}$ & Própria & Doação & $\begin{array}{l}\text { Sim, auxílio } \\
\text { técnico }\end{array}$ & $\begin{array}{l}\text { Não sei, pois } \\
\text { foi doada }\end{array}$ \\
\hline
\end{tabular}




\begin{tabular}{|c|c|c|c|c|c|c|}
\hline & & $\begin{array}{l}\text { Melão, } \\
\text { Pimentão, } \\
\text { Alface. }\end{array}$ & & & & \\
\hline Uruçuí-PI & $100 \mathrm{~m}^{2}$ & $\begin{array}{l}\text { Melancia, } \\
\text { Abóbora, } \\
\text { Batata, } \\
\text { Coentro, } \\
\text { Pimenta, } \\
\text { Melão, } \\
\text { Pimentão, } \\
\text { Alface. }\end{array}$ & Própria & Doação & $\begin{array}{l}\text { Sim, auxilio } \\
\text { técnico }\end{array}$ & $\begin{array}{l}\text { Não sei, pois } \\
\text { foi doada }\end{array}$ \\
\hline Uruçuí-PI & 1 hectare & $\begin{array}{l}\text { Melancia, } \\
\text { Abóbora, } \\
\text { Batata, } \\
\text { Coentro, } \\
\text { Pimenta, } \\
\text { Melão, } \\
\text { Pimentão, } \\
\text { Alface. }\end{array}$ & Própria & Herança & Não & 240 reais \\
\hline $\begin{array}{l}\text { Benedito } \\
\text { Leite- MA }\end{array}$ & $\begin{array}{l}300 \\
\text { metros }\end{array}$ & $\begin{array}{l}\text { Melancia, } \\
\text { Abóbora, } \\
\text { Batata, } \\
\text { Coentro, } \\
\text { Pimenta, } \\
\text { Melão, } \\
\text { Pimentão, } \\
\text { Alface. }\end{array}$ & Própria & Doação & Não & $\begin{array}{l}\text { Não sei, pois } \\
\text { foi doada }\end{array}$ \\
\hline
\end{tabular}

Fonte: Própria (2018).

Há a constatação da timidez das atividades expressa através da pouca área cultivada, tabela 3, e a expansão dessa atividade poderia contribuir com a melhoria da qualidade de vida das pessoas envolvidas e da economia local como um todo, à medida que poderiam contar com a produção local para atender as necessidades da população.

É possível observar que os produtores não fizeram a compra da área que atualmente cultivam. $80 \%$ desses receberam através de doação e $20 \%$ através de herança. Esse fato, associado ao de que $40 \%$ afirmaram receber apoio do governo através de auxílio técnico mostra um direcionamento das políticas públicas para essa atividade, apesar de insuficientes.

Quanto ao preço do hectare de terra em locais apropriados para o cultivo de hortaliças, que apenas um produtor afirmou ter conhecimento, em 2006, o hectare custou 3.000 reais. De acordo com as informações da figura 2 , o valor do hectare de terra nesse mesmo período variava nessa mesma média. A presença do agronegócio no município de Uruçuí causou a especulação fundiária. De acordo com Reydon e Monteiro (2006), em meados de 1990, 30,7\% da área total do município estava concentrada em apenas 5 (cinco) unidades produtoras. A partir dessa concentração e do cultivo da soja, o valor do hectare ficou supervalorizado, comparando com 
o período em que a demanda e as motivações de aquisições não eram predominantes do cenário do agronegócio.

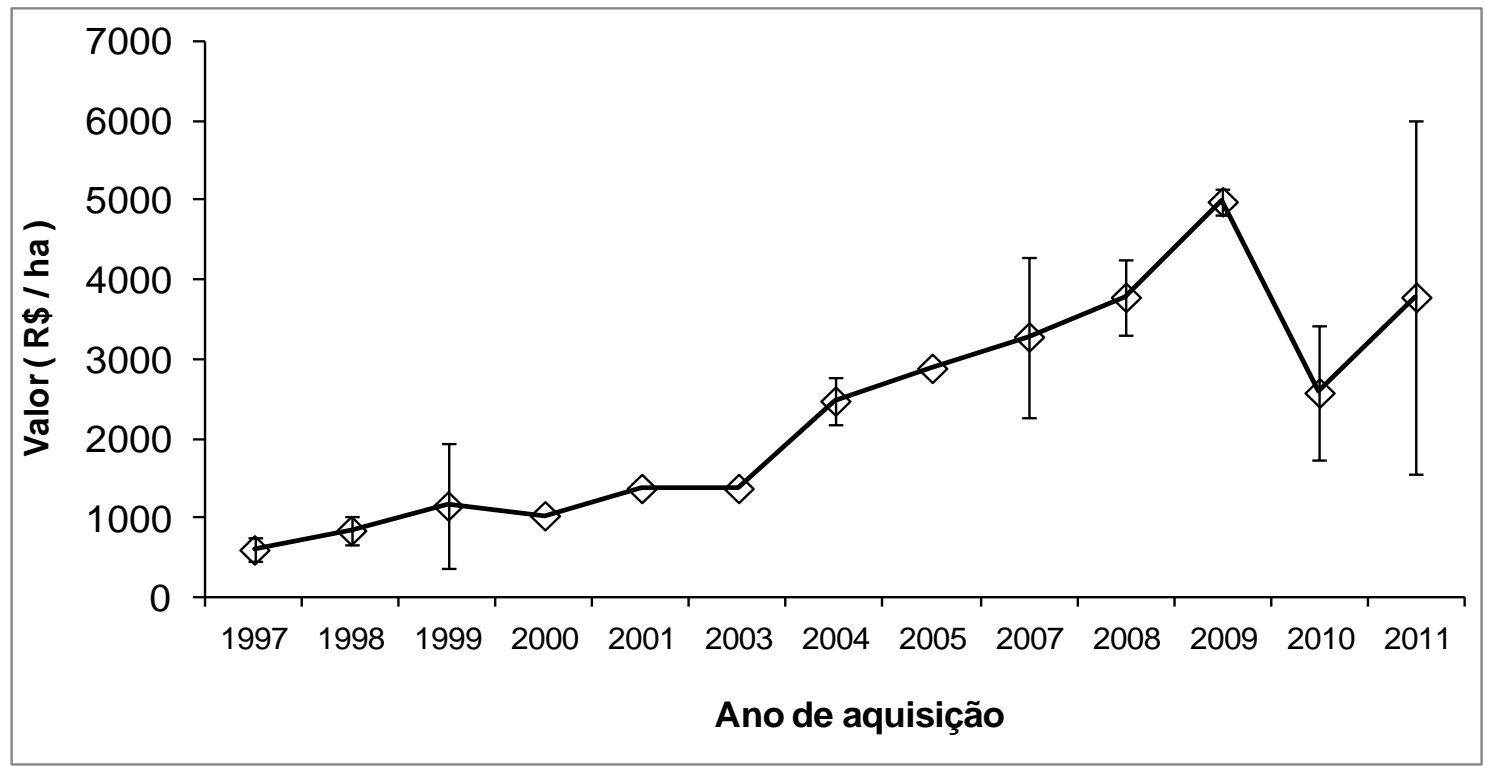

Figura 2: Preço médio de venda de um hectare de terra, barras representam o Desvio Padrão da média, no município de Uruçuí-PI, período de 1997 a 2011 - R \$ de 2014.

Fonte: RODRIGUES (2015).

$\mathrm{Na}$ tabela 4, verifica-se que o início das atividades oscilou de forma bem significativa (1985-2018), sem muitos avanços na prática. Todas as unidades de produção de hortaliças fazem parte de representantes da agricultura familiar, uma vez que atendem os requisitos, desde os associados à dimensão da área cultivada até os que se relacionam a sua operacionalização como mão de obra.

$\mathrm{Na}$ literatura, os representantes da agricultura familiar são apresentados como responsáveis por parcelas bem significativas da produção da alimentação que chega à mesa dos brasileiros; o agricultor familiar e empreendedor familiar rural é aquele que pratica atividades no meio rural (ARAÚJO, 2013), atendendo, aos seguintes requisitos, de forma simultânea, conforme destaca Araújo (2013):

I - não detenha área superior a 4 (quatro) módulos fiscais;

II - utilize predominantemente mão de obra do núcleo familiar nas atividades econômicas do seu estabelecimento ou empreendimento;

III - tenha percentual mínimo da renda familiar oriundo de atividades econômicas do seu empreendimento, na forma definida pelo Poder Executivo;

IV - seja responsável pela gestão do estabelecimento ou empreendimento com sua família. 
São quatro módulos fiscais que variam entre 20 hectares, se situados na proximidade de capitais, e 400 hectares, extensão de área bastante corriqueira na região amazônica. No caso do Município de Uruçuí, o módulo fiscal corresponde a 75 (setenta e cinco) hectares.

As principais hortaliças cultivadas pelos agricultores familiares são: Melancia, Abóbora, Batata, Coentro, Pimenta, Melão, Pimentão e Alface.

Tabela 4: Variáveis de comercialização e viabilidade econômica da produção de hortaliças

\begin{tabular}{|c|c|c|c|c|c|}
\hline $\begin{array}{c}\text { Início da } \\
\text { comercialização }\end{array}$ & $\begin{array}{l}\text { Envolvimento do } \\
\text { núcleo familiar }\end{array}$ & $\begin{array}{l}\text { Dificuldades na } \\
\text { comercialização }\end{array}$ & $\begin{array}{c}\text { Uso de } \\
\text { agrotóxico }\end{array}$ & $\begin{array}{c}\text { Renda } \\
\text { complementar }\end{array}$ & $\begin{array}{c}\text { Suficiência da } \\
\text { atividade para } \\
\text { sustento da família }\end{array}$ \\
\hline 2018 & Somente auxílio & $\begin{array}{l}\text { Assistência } \\
\text { técnica }\end{array}$ & Não & Não & Não \\
\hline 1985 & Somente auxílio & $\begin{array}{l}\text { Suportes para } \\
\text { acomodar as } \\
\text { mudas; } \\
\text { Assistência } \\
\text { técnica; } \\
\text { Transporte }\end{array}$ & Não & Não & Não \\
\hline 2015 & Somente auxílio & $\begin{array}{l}\text { Assistência } \\
\text { técnica; } \\
\text { Transporte }\end{array}$ & Não & Não & Não \\
\hline 2006 & Somente auxílio & $\begin{array}{l}\text { Transporte; } \\
\text { Adubação }\end{array}$ & Não & Aposentado & Sim \\
\hline 2017 & Somente auxílio & $\begin{array}{l}\text { Assistência } \\
\text { técnica; } \\
\text { Transporte }\end{array}$ & Não & Não & Não \\
\hline
\end{tabular}

Fonte: Própria (2018).

Quanto às dificuldades apresentadas pelos produtores para a comercialização, estas mostram fragilidades que poderiam ser minimizadas com a formação de associação, a qual poderia evoluir para uma cooperativa. Associada a essa ação, a atuação de políticas públicas de apoio com suporte técnico efetivo também são fundamentais para a manutenção e evolução das atividades do grupo.

Apesar da importância e representatividade da agricultura familiar, seus representantes tem encontrado muitas dificuldades em manter as atividades com rendimentos significativos, principalmente quando a área cultivada é pequena, como o caso dos produtores em estudo. Apenas $20 \%$ dos produtores possuem outra renda e $80 \%$ afirmaram que a renda é insuficiente para o sustento da família. 
Destaca-se que os produtores não fazem uso de agrotóxico nas suas atividades de cultivo de hortaliças, podendo, assim, caracterizar uma prática de cultivo orgânico. Levou décadas para se confirmarem as evidências de que os agrotóxicos são ruins para a saúde e o meio ambiente, estando associados ao desenvolvimento de câncer, impactos aos sistemas neurológico, reprodutivo e endócrino, entre outros males (LOPES; ALBUQUERQUE, 2018).

Como se verifica na figura 3, as principais hortaliças cultivadas pelos produtores em análise são: Melancia (Citrullus lanatus - Thunb. Matsum. e Nakai), Abóbora (Cucurbita moschata Duch), Batata doce (Ipomoea batatas L), Coentro (Coriandrum sativum L), Pimenta de cheiro (Capsicum chinense Jack), Melão (Cucumis melo L), Pimentão (Capsicum annuum L.) e Alface (Lactuca sativa $L$ ).

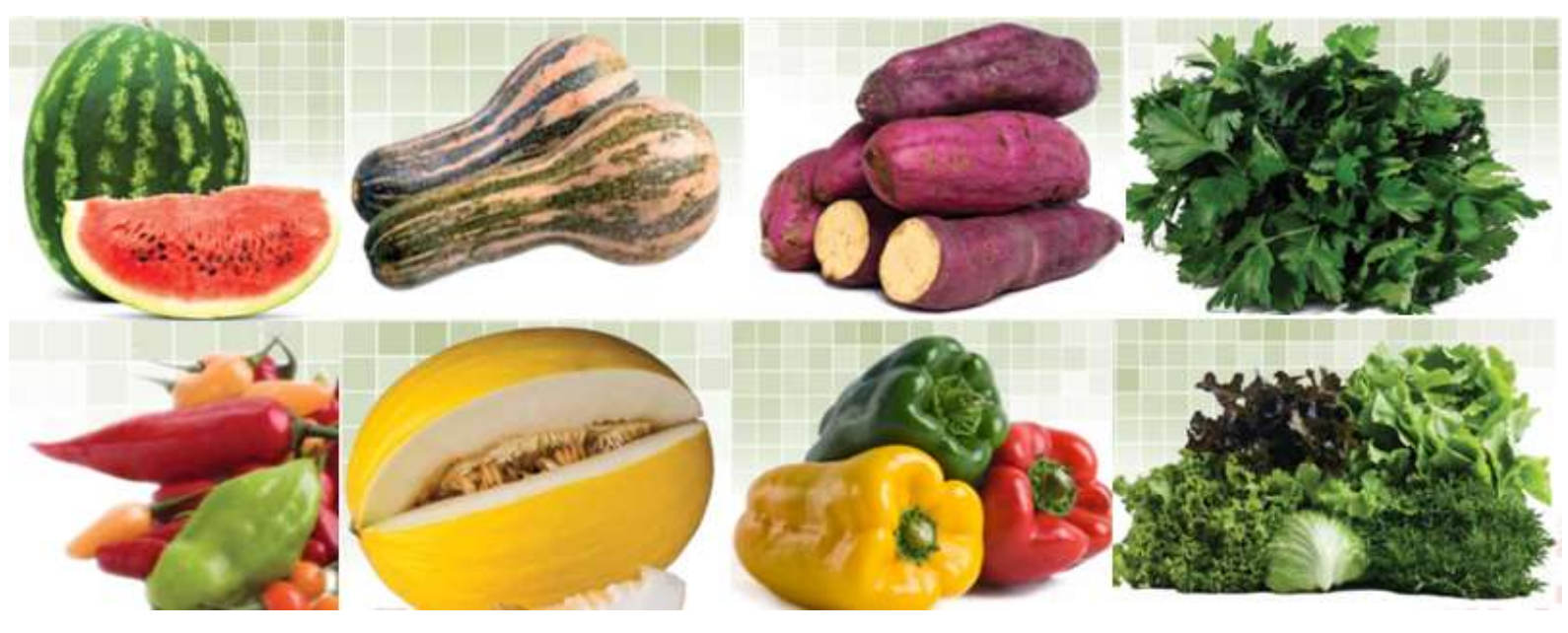

Figura 3: Principais hortaliças cultivas pelos agricultores familiares de Uruçuí-PI. Fonte: Própria (2018).

\section{Conclusões}

A produção de hortaliças é feita exclusivamente por representantes da agricultura familiar, direcionando para a necessidade de organização em forma de associação ou cooperativa.

Há predominância de pessoas do município de Uruçuí-PI, o que mostra indicativo de desenvolvimento endógeno, apesar de ainda não ter se consolidado como tal, tendo em vista a necessidade de apoio de políticas públicas para a maior atuação desses produtores e representatividade local. 
Os resultados mostraram que há necessidade de intervenção de políticas públicas para apoiar o grupo de produtores, preferencialmente em um espaço unificado, com a finalidade de dar maior visibilidade à produção local, e contribuir para a expansão tanto da quantidade produzida quanto da população que frequenta o mercado municipal para fazer a compra dos produtos.

\section{Referências}

ARRAES R. A.; TELES, V. K. Endogeneidade versus Exogeneidade do Crescimento Econômico: uma análise comparativa entre nordeste, Brasil e países selecionados. Revista Econômica do Nordeste, Fortaleza, v. 31, n. Especial, p. 754-776, nov. 2000. Disponível em: $<$ http://www.repositorio.ufc.br/bitstream/riufc/2259/1/2000_art_rarraes.pdf>. Acesso em: 23 nov. 2018.

ARAÚJO, M. J. Fundamentos de agronegócios. 4. ed. São Paulo: Atlas, 2013.

BALEM, T. A. Associativismo e cooperativismo. Santa Maria: Universidade Federal de Santa Maria, Colégio Politécnico, 2016. 97 p.

BITTENCOURT, G. A. Abrindo a caixa preta: o financiamento da agricultura familiar no Brasil, 2003. Dissertação (Mestrado em Desenvolvimento Econômico, Espaço e Meio ambiente) - Universidade Estadual de Campinas. Instituto de Economia, Campinas, SP, 2003.

BUSSAB, O.; MORETTIN, P. A. Estatística básica. 6. ed. São Paulo: Saraiva, 2010.

CALladO, A. A. C. Agronegócio. São Paulo: Atlas, 2005.142 p.

DIEHL, Astor Antônio; TATIM, Denise Carvalho. Pesquisa em ciências sociais aplicadas: métodos e técnicas. São Paulo: Prentice Hall, 2004.

GUALDA, N. L. P. Agricultura familiar versus modelo agroexportador: o falso dilema da não coexistência. Sociedade Brasileira de Economia, Administração e Sociologia Rural, Brasília, DF, 2008. Disponível em: http://www.sober.org.br/palestra/6/368.pdf. Acesso em: 02 nov. 2018.

HESPANHOL, A. N. Desafio da geração de renda em pequenas propriedades e a questão do desenvolvimento rural sustentável no Brasil. In: ALVES, Adilson Francelino; CARRIJO, Beatriz Rodrigues; CANDIOTTO, Luciano Zanetti Pessoa (Orgs.). Desenvolvimento territorial e agroecologia. São Paulo: Expressão popular, 2008. p. 81-93.

IBGE. Censo Agropecuário 2006. Brasil, grandes regiões e Unidades da Federação. Disponível em:

<http://www.ibge.gov.br/home/estatistica/economia/agropecuaria/censoagro/brasil_2006/Bras il_censoagro2006.pdf. Acesso em: 12 mar. 2019. 
LOPES, C. V. A.; ALBUQUERQUE, G. S. C. de. Agrotóxicos e seus impactos na saúde humana e ambiental: uma revisão sistemática. Revista Saúde debate 42 (117) Apr-Jun 2018.

MDA. Ministério do Desenvolvimento Agrário (2012). Disponível em: http://www.mda.gov.br/portal. Acesso em: 12 mar. 2018.

NEVES, D. P. Agricultura familiar: quantos ancoradouros. In: FERNANDES, B. M.; MARQUES, M. I. M.; SUZUKI, J.C. (Orgs.). Geografia agrária: teoria e poder. São Paulo: Expressão Popular, 2007. p. 211-270. Disponível em: <http://www2.prudente.unesp.br/dgeo/nera/Bernardo2006_bibliografia/Agricultura_Familiar. pdf. Acesso em: 2 nov. 2018.

REYDON, B. P.; MONTEIRO, M. S. L. A ocupação do cerrado piauiense: um processo de valorização fundiária. In: REYDON, B. P; CORNÉLIO, F. N. M. Mercados de terras no Brasil: estrutura e dinâmica. Brasília, DF: NEAD, 2006. p. 95-121.

RODRIGUES, M. A. Caracterização socioeconômica da produção primária da cadeia produtiva da soja no município de Uruçuí-Pi. Dissertação (mestrado) - Universidade Federal do Ceará, Centro de Tecnologia. Programa de Pós-Graduação em Logística e Pesquisa Operacional. Fortaleza, 2015.

RODRIGUES, M. A.; DINIZ, F. O.; SOUSA, A. H. R. Cooperativismo agrícola: o caso da Cooperativa de Nova Santa Rosa em Uruçuí-PI. Enciclopédia Biosfera, Goiânia, v. 9, n. 16; p. 2487, 2013.

SOUSA, J. M. P. Avaliação do financiamento da agricultura familiar na produção, ocupação e renda. 2008. 179 f. Dissertação (Mestrado Profissional em Avaliação de Políticas Públicas) - Universidade Federal do Ceará, Fortaleza, 2008. 